\title{
IMPRESIONES EN TORNO AL INFORME DE FISCALIZACIÓN DEL TRIBUNAL DE CUENTAS SOBRE LA CONTABILIDAD ELECTORAL DE LAS ÚLTIMAS ELECCIONES GENERALES
}

\author{
José María Coello de Portugal \\ Dpto. de Derecho Constitucional \\ Universidad Complutense de Madrid \\ jmcoello@der.ucm.es
}

\section{CONTENIDO DE LA RESOLUCIÓN}

El pasado sábado día 11 de mayo de 2013, el Boletín Oficial del Estado publicaba una importante resolución de las Cortes Generales titulada Resolución de 9 de abril de 2013, aprobada por la Comisión Mixta para las Relaciones con el Tribunal de Cuentas en relación con el Informe de fiscalización de la contabilidad de las Elecciones a Cortes Generales, celebradas el 20 de noviembre de 2011. Resolución parlamentaria que, bajo tan tronante denominación legal, refleja algo así como los resultados del examen de transparencia financiera de las cuentas de los partidos políticos, coaliciones, federaciones y agrupaciones de electores que concurrieron a las últimas elecciones generales celebradas en España, con fecha 20 de noviembre de $2011^{1}$.

La cuestión no pasaría de ahí si no fuera por el superlativo aumento del interés ciudadano - aumento indudablemente causado por la situación de fuerte crisis económica que estamos viviendo- en relación con la financiación de los partidos políticos y por la renovada conciencia ciudadana de que las actividades de las formaciones políticas son casi íntegramente sostenidas con los fondos públicos que, a través del Estado, pasan del bolsillo del contribuyente a las cuentas corrientes de los partidos políticos. Cuentas sobre las que en todas las democracias europeas existe una creciente demanda ciudadana de transparencia financiera y buena administración.

Debemos recordar — simplificando la cuestión al máximo- que los partidos políticos reciben del Estado de forma estable tres importantes partidas de ayudas económicas que componen el grueso de su financiación:

${ }^{1}$ Elecciones convocadas por el Real Decreto 1329/2011, de 26 de septiembre, de disolución del Congreso de los Diputados y del Senado y de convocatoria de elecciones. 
una primera dirigida al sostenimiento de su estructura y actividades ordinarias, otra afectada al sostenimiento de los gastos extraordinarios que se generan a propósito de los diversos procesos electorales ${ }^{2}$ y, finalmente, una tercera fuente de financiación de naturaleza parlamentaria que no constituye exactamente financiación a partidos políticos, sino a los grupos de las Cámaras, pero que indirectamente redunda también en la utilidad de estas formaciones y de su acción política. Es, fundamentalmente, a la segunda y tercera de estas partidas a las que se refiere la Resolución de 9 de abril de 2013 dictada por las Cortes Generales que, tras un largo proceso de control financiero, radiografía con relativa precisión el coste del último proceso de elecciones generales para el bolsillo de los españoles, así como la utilización de estos recursos públicos por parte de nuestros representantes.

\section{LA RELEVANCIA JURÍDICA DE UNA SUBVENCIÓN ECONÓMICA}

No es éste momento de recordar la trascendencia de la financiación de las agrupaciones políticas para el funcionamiento de la democracia contemporánea, ni el lugar para la definición del dogma de la transparencia financiera de las cuentas de los partidos políticos como premisa para el adecuado funcionamiento del régimen democrático ${ }^{3}$. Baste aludir negativamente a una evidencia que refleja de forma muy simple esta circunstancia: la quiebra de la legalidad en la financiación de los partidos políticos implica la introducción de competencia desleal entre las formaciones políticas concurrentes a la elección, genera una ruptura de la igualdad en la obtención del mandato parlamentario que falsea la representación y la voluntad popular, favorece la corrupción administrativa una vez alcanzado el poder y, en última instancia, implica una descomposición de la transparencia en el acceso al poder propia del régimen democrático.

\footnotetext{
${ }^{2}$ Para un estudio detallado sobre financiación de las elecciones puede consultarse Emilio Pajares Montolío, La financiación de las elecciones, Madrid, Congreso de los Diputados, 1998. Para un estudio detallado sobre financiación de las formaciones políticas puede consultarse la obra de María Holgado GonzÁLEZ, La financiación de los partidos políticos en Espa$\tilde{n} a$, Col. Tirant monografías, Valencia, Tirant lo Blanch, 2003.

3 «La falta de una ordenación jurídica completa que garantice la transparencia de la actividad económica partidista y la deficiencia de procedimientos e instrumentos jurídicos apropiados a fin de conocer quién sostiene económicamente a cada partido contribuyen a aumentar el grado de corrupción política». Cfr. Bernardino Esparza Martínez, Crisis democrática en los partidos políticos, México DF, Cárdenas editor y distribuidor, 1999, p. 96.
} 
Estas razones bastarían ya para advertir la relevancia jurídico-constitucional de este Informe de fiscalización y de la acción de control financiero del Tribunal de Cuentas sobre los partidos; pero podemos sumar a las anteriores dos razones más, de índole cuantitativo y cualitativo. Cuantitativamente $-\mathrm{y}$ pese a la reducción a la financiación electoral impuesta por la profunda crisis económica internacional en cuyo contexto nos encontramos inmersos-, la importancia de este Informe de fiscalización se desprende de la magnitud de sus cifras y del simple vistazo a las cantidades con las que el Estado ha subvencionado a las formaciones políticas durante este último proceso electoral:

a) La financiación pública ha entregado a las formaciones políticas en España 21.633,33 euros por cada escaño alcanzado en el Congreso de los Diputados o en el Senado, así como 0,83 euros por cada uno de los votos obtenidos por cada candidatura al Congreso, uno de cuyos miembros - al menos - hubiera obtenido escaño como diputado; más otros 0,33 euros por cada uno de los votos obtenidos por cada candidato que hubiera obtenido escaño de senador.

b) También nos recuerda el Informe que el Estado ha subvencionado a los partidos por los gastos originados por el envío directo y personal a los electores de sobres y papeletas de propaganda electoral —siempre que la candidatura presentada a la elección hubiera obtenido el número de diputados, senadores o votos preciso para constituir un grupo parlamentario en una u otra Cámara- y que su vez la obtención de grupo parlamentario en una u otra Cámara ha dado derecho a estos grupos a la obtención de una subvención por una sola vez, siendo la cuantía a abonar de 0,22 euros por elector.

Por otra parte, en un sentido cualitativo para el estado de nuestro régimen democrático, este Informe de fiscalización afecta a nuestra clase política en pleno y nos informa de que en las últimas elecciones generales han sido diecinueve las formaciones políticas que han alcanzado los requisitos legalmente exigidos para percibir subvenciones, obteniendo representación parlamentaria en el Congreso de los Diputados o en el Senado. Dato importante porque estas entidades ${ }^{4}$, en conjunto, representan una espe-

${ }^{4}$ Por orden alfabético estas formaciones han sido: Amaiur, Bloc-Iniciativa-Verds-EquoCoalició Compromís, Bloque Nacionalista Galego, Coalición Canaria-Agrupación Herreña Independiente-Nueva Canarias, Coalición Canaria-Nueva Canarias, Convergència i Unió, Entesa pel Progrés de Catalunya, Esquerra Republicana de Catalunya-Catalunya Sí, Eusko Alderdi Jetzalea-Partido Nacionalista Vasco, Foro Ciudadanos, Geroa Bai, la Izquierda Plu- 
cie tabla desagregada del pluralismo político en nuestro país y todas juntas constituyen el plenario de quienes concurren a la formación y manifestación de la voluntad popular en España a través de las instituciones de democracia representativa.

\section{PROCEDIMIENTO DE FISCALIZACIÓN, CONCLUSIONES Y RECOMENDACIONES DEL INFORME DE FISCALIZACIÓN EMITIDO POR EL TRIBUNAL DE CUENTAS}

\section{Procedimiento de fiscalización}

Ha sido el Pleno del Tribunal de Cuentas quien, en su informe de fiscalización emitido en ejercicio de la función que le atribuye el art. 134 de la Ley Orgánica 5/1985, de 19 de junio, del Régimen Electoral General, ha recordado de forma muy oportuna cómo el marco legal de su actuación fiscalizadora viene presidido por un doble deber dotado, a su vez, de una doble consecuencia jurídica. Por una parte, el deber impuesto a todas las formaciones políticas sujetas a fiscalización de presentar a este órgano una contabilidad detallada y documentada de sus respectivos ingresos y gastos electorales; deber que tiene por consecuencia el pronunciamiento del Tribunal acerca de la regularidad formal de estas contabilidades electorales presentadas por las diversas formaciones. Y, por otra parte, el deber de las formaciones políticas de evitar incurrir en irregularidades o violaciones de las restricciones establecidas en materia de ingresos y gastos ${ }^{5}$ electorales que, en caso de producirse, tendrán por consecuencia el ejercicio por parte del Tribunal de Cuentas de la facultad de proponer la no adjudicación o la reducción de la subvención pública a la formación política infractora. Circunstancias ambas que, debidamente fiscalizadas por el Tribunal y motivadas en su Informe de fiscalización, han sido objeto de envío por parte del Tribunal de Cuentas al gobierno y a la Comisión Mixta Congreso-Senado para las relaciones con el Tribunal de Cuentas.

ral, Partido Popular, Partido Popular en coalición con el Partido Aragonés, Partido PopularExtremadura Unida, Partido Socialista Obrero Español, Partit del Socialistes de Catalunya, Unión del Pueblo Navarro en coalición con el Partido Popular, Unión, Progreso y Democracia.

${ }^{5}$ Límites que para las últimas elecciones generales se fijaron por la Orden EHA/2608/2011, de 29 de septiembre, por la que se fijan las cantidades actualizadas de las subvenciones electorales y del límite de gastos electorales. 
Para el alcance de los anteriores objetivos de control financiero, la fiscalización del Tribunal de Cuentas ha venido precedida, entre otras muchas medidas, de la recepción de la contabilidad facilitada por todas las formaciones políticas obligadas a rendirla junto con sus soportes documentales, por la identificación de la procedencia de todos los recursos empleados por los partidos para financiar el proceso electoral, por la identificación de las personas físicas o jurídicas aportadoras y por la fiscalización del cumplimiento del límite máximo ${ }^{6}$ por parte de estas personas, por la verificación del respeto de la prohibición a los partidos de obtener fondos de Administraciones Públicas o personas concesionarias de estas Administraciones, así como por la fiscalización del ingreso de todas estas cantidades de dinero en cuentas abiertas por las formaciones políticas, específicamente, para las elecciones generales. Medidas todas unidas a la genérica limitación de gasto electoral ${ }^{7}$ impuesta a todas las formaciones políticas ${ }^{8}$.

\section{Conclusiones del Informe de fiscalización}

De las mismas, podemos extraer algunos datos especialmente reveladores del estado de transparencia financiera de estas formaciones.

En primer lugar, debemos felicitarnos porque el Tribunal de Cuentas nos recuerda que todas las formaciones obligadas a la presentación de su contabilidad electoral han cumplido con este deber, así como que el grueso de las formaciones ha realizado sus operaciones en cuentas específicas abiertas al efecto?.

610.000 euros.

7 Limitación sobre el gasto electoral sobre la que ha señalado Gaspar Ariño Ortiz que «ha sido un objetivo muchas veces proclamado por los partidos y nunca logrado». Cfr. Gaspar AriÑo Ortiz, La financiación de los partidos políticos, Madrid, Foro de la Sociedad CivilCinca, 2009, p. 42.

${ }^{8}$ Limitación que para estas elecciones ha consistido en la prohibición de superar el límite máximo resultante de multiplicar por 0,33 euros el número de habitantes correspondientes a la población de derecho de las circunscripciones donde cada una de las formaciones presente sus candidaturas. Limitación que también se ve completada con una limitación del gasto por publicidad electoral en prensa periódica y emisoras de radio privadas, que no podría exceder del 20 por 100 del límite máximo de gastos. Límite en cuyo beneficio cada formación política ha debido contabilizar y presentar de forma diferenciada los gastos de esta naturaleza en que hubiera podido incurrir.

${ }^{9}$ Conclusiones primera y sexta del informe de fiscalización. 
En segundo lugar, los españoles podemos saber gracias a este Informe ${ }^{10}$ que, en las anteriores elecciones generales, las formaciones políticas que concurrieron a la elección declararon unos recursos públicos recibidos de, exactamente, 62.719 .000 euros.

En tercer lugar, podemos felicitarnos porque ninguna formación política sobrepasó el límite máximo de gastos previsto en el art. 175.2 de la Ley Orgánica 5/1985, de 19 de junio, del Régimen Electoral General, aunque, lamentablemente, no podamos decir lo mismo respecto de los sublímites establecidos en los arts. 55 y 58 relativos a gastos de publicidad exterior y en prensa y radio. Incumplimientos cuya cuantía no es especialmente preocupante en términos cuantitativos ${ }^{11}$, pero que, por su importancia cualitativa, el Tribunal de Cuentas ha estimado suficientes como para proponer una disminución de la subvención electoral ${ }^{12}$; por lo que el Tribunal formula sendas propuestas ${ }^{13}$ de reducción a las formaciones políticas incumplidoras ${ }^{14}$, sin duda de más importancia pedagógica que económica.

En cuarto lugar, en relación con la transparencia del sector privado implicado en la contabilidad electoral, resulta destacable el mal dato de que un total de veintisiete empresarios no cumplieron con su obligación de rendir al Tribunal de Cuentas información detallada sobre la facturación realizada a los partidos políticos por importes superiores a 10.000 euros, tal y como dispone la Ley Orgánica 5/1985, de 19 de junio, del Régimen Electoral General en su art. 133.5, resultando un saldo total no informado al Tribunal de Cuentas de 1.235.797,70 euros. Cantidad esta nada despreciable y de la que no se puede culpar a la falta de transparencia de las formaciones políticas - sino a los sectores privados que colaboran con ellasy de la que, por su carácter intolerable, el Tribunal de Cuentas, a propuesta del Ministerio Fiscal, acuerda dar traslado a la Junta Electoral Central ${ }^{15}$.

${ }^{10}$ Conclusión segunda del informe de fiscalización.

${ }^{11}$ La formación política Geroa Bai excedió el sublímite en 12.312,36 euros en relación con la publicidad exterior, mientras que el sublímite para gastos de publicidad en prensa y radio fue excedido por el Partido Popular en 54.142,43 euros y por Geroa Bai en unos insignificantes 56,46 euros.

${ }_{12}$ Conclusión cuarta del informe de fiscalización.

13 Conclusión séptima del informe de fiscalización.

${ }^{14}$ Los importes de reducción son de 2.522,22 euros en el caso de Geroa Bai y de 4.349,05 euros en el caso del Partido Popular.

${ }^{15}$ Conclusión sexta del informe de fiscalización. 


\section{Recomendaciones del Tribunal de Cuentas}

El Tribunal de Cuentas, en ejercicio de su función constitucional, una vez analizada la contabilidad electoral de las formaciones políticas que hubieron concurrido a las elecciones generales y a la vista de las conclusiones de su Informe, formula una serie de recomendaciones que, a su entender, resultan procedentes para garantizar una mayor eficacia del control externo de los ingresos y gastos electorales. Recomendaciones que, a nuestro juicio, resultan de sumo interés y que, en síntesis, son las siguientes:

1. Recomendar la limitación, por parte de las formaciones políticas, de sus gastos - especialmente en el actual contexto de crisis económica- «a los imprescindibles para acometer la campaña electoral ajustándose a una interpretación estricta de los conceptos subvencionables» ${ }^{16}$ en sintonía con la reducción del gasto electoral acordada por la Ley Orgánica 2/2011, de 28 de enero. Del mismo modo, se recomienda a las formaciones políticas la previsión de un sistema de control interno orientado a la selección de la oferta económica más ventajosa en relación con sus gastos de gran cuantía, o de aquellos concentrados en un mismo proveedor.

2. Recomendar la adecuación del límite legal de gastos en publicidad exterior de los partidos y en prensa periódica y emisoras de radio de titularidad privada a los nuevos soportes de publicidad introducidos por las nuevas tecnologías, fundamentalmente en relación con la publicidad en prensa digital y los anuncios en internet, eliminando incertidumbres interpretativas.

3. Recomendar implantar, sin perjuicio de otras que procedan, las debidas sanciones a terceros (entidades financieras y proveedores) que incumpliesen su obligación de colaboración con el Tribunal de Cuentas, por faltar a su deber de remisión de información en relación con las campañas electorales.

Como se ve, las anteriores recomendaciones del Tribunal, lejos de ser únicamente recomendaciones de legalidad, han transitado también por la senda de la oportunidad, tratando de favorecer, en la coyuntura presente - y para el futuro-, el régimen normativo de la transparencia y el control financiero de ingresos y gastos electorales de las formaciones políticas.

${ }^{16}$ Recomendación primera del informe de fiscalización. 
Régimen al que, en opinión del Tribunal, hacen falta ajustes en un triple sentido que marca una triple llamada de atención al legislador, a los partidos políticos y a los agentes privados. Llamada de atención al legislador en materia de adaptación de las normas en vigor a la realidad social (por ejemplo en materia de publicidad electoral mediante nuevas tecnologías), llamada de atención a los partidos políticos en materia de adaptación a la coyuntura económica (especialmente en materia de austeridad y procesos de contratación y selección de ofertas) y llamada de atención a los agentes privados en relación con el endurecimiento de las sanciones previstas para aquellos empresarios (especialmente entidades financieras y proveedores) que incumpliesen con su deber legal de colaboración con el Tribunal de Cuentas, negándole el suministro de la información necesaria para el control de la actividad financiera de los partidos preparatoria de las elecciones. Intolerable conducta de estos agentes privados que favorece la opacidad contable e impide la fiscalización del dinero entregado a estas formaciones para afrontar sus gastos electorales y que, en el caso de encubrir fraude, corrupción o promesa de favores presentes o futuros del partido al administrado una vez alcanzado el poder - indicio que no puede descartarse cuando el agente privado se niega a entregar su información- afecta no sólo al orden público por razones de transparencia fiscal y contable, que también, sino sobre todo por razones de transparencia en el proceso de elección de representantes, de limpieza en el resultado de la elección y de potencial deterioro del núcleo de principios esenciales e inderogables que presiden el acceso al poder en un régimen democrático.

\section{POSICIÓN DE LA COMISIÓN MIXTA DE LAS CORTES GENERALES EN RELACIÓN CON EL INFORME DE FISCALIZACIÓN DEL TRIBUNAL DE CUENTAS}

Debemos, por último, reparar en la postura tomada por la Comisión Mixta de las Cortes Generales para las Relaciones con el Tribunal de Cuentas ${ }^{17}$ en relación con el Informe de fiscalización emitido por el Tribunal. Con carácter preliminar debemos felicitarnos de la sintonía existente entre el supremo órgano fiscalizador de las cuentas del Estado y las Cortes Generales, en la medida en que la Resolución de la Comisión Mixta de las Cortes Generales en realidad tiene por base fundamental en sus consi-

17 Adoptada en su sesión de 9 de abril de 2013. 
deraciones al gobierno, al propio Tribunal de Cuentas y a las formaciones políticas, lo ya apuntado en el Informe de fiscalización emitido por el Tribunal de Cuentas como supremo órgano fiscalizador de las cuentas y de la gestión económica del Estado.

Así, las Cortes Generales, a través de su Comisión Mixta, recomiendan formalmente al gobierno en primerísimo lugar el acometimiento de un régimen sancionador para las entidades financieras y proveedores incumplidores de sus obligaciones de información al Tribunal de Cuentas. Recomendación que la Comisión Mixta transformará luego en instancia al gobierno para la modificación de la Ley Orgánica 8/2007, de 4 de julio, sobre Financiación de Partidos Políticos a efectos de tipificación como infracción la falta de colaboración con el Tribunal de Cuentas. Por otra parte, se acuerda recomendar al ejecutivo proceder al desarrollo reglamentario de los distintos tipos de gasto electoral previstos en el ordenamiento jurídico ${ }^{18}$, así como instarle a acometer este desarrollo normativo, teniendo en cuenta la doctrina del Tribunal de Cuentas en relación con estos conceptos de gasto electoral. De forma igualmente oportuna, se insta también al ejecutivo al desarrollo de las normas electorales en relación con la inclusión de los nuevos soportes de comunicación vinculados a las nuevas TIC's, así como a la inclusión de los límites de gasto en publicidad exterior y prensa a otros soportes publicitarios relacionados con las nuevas tecnologías. Consideraciones todas que van en la línea de mejorar la transparencia de la financiación electoral y de impedir los incumplimientos de los partidos — culposos o dolosos— que sin duda redundarán también en la segu-

18 Art. 130 de la Ley Orgánica 5/1985, 19 junio, del Régimen Electoral General, redactado por LO 8/1991, de 13 de marzo: «Se consideran gastos electorales los que realicen los partidos, federaciones, coaliciones o agrupaciones participantes en las elecciones desde el día de la convocatoria hasta el de la proclamación de electos por los siguientes conceptos:

a) Confección de sobres y papeletas electorales.

b) Propaganda y publicidad directa o indirectamente dirigida a promover el voto a sus candidaturas, sea cual fuere la forma y el medio que se utilice.

c) Alquiler de locales para la celebración de actos de campaña electoral.

d) Remuneraciones o gratificaciones al personal no permanente que presta sus servicios a las candidaturas.

e) Medios de transporte y gastos de desplazamiento de los candidatos, de los dirigentes de los partidos, asociaciones, federaciones y coaliciones, y del personal al servicio de la candidatura.

f) Correspondencia y franqueo.

g) Intereses de los créditos recibidos para la campaña electoral, devengados hasta la fecha de percepción de la subvención correspondiente.

b) Cuantos sean necesarios para la organización y funcionamiento de las oficinas y servicios precisos para las elecciones». 
ridad jurídica de aquellas formaciones políticas que — hay que presumirdesean atender adecuadamente sus obligaciones legales.

Seguidamente y en otro orden de cosas, la Comisión Mixta de las Cortes Generales insta al propio Tribunal de Cuentas a continuar potenciando en su organización interna los recursos humanos destinados a la unidad de fiscalización de los partidos políticos, a efectos de que los Informes correspondientes a la contabilidad ordinaria de las formaciones políticas puedan ser aprobados en el ejercicio siguiente al de su rendición al propio Tribunal de Cuentas, e igualmente se anima al Tribunal por parte de las Cortes Generales a continuar identificando a los proveedores y a otros sujetos que mantengan relaciones económico-financieras con los partidos políticos e incumplan su deber de colaboración, aportando esta información también a la Junta Electoral Central.

Finalmente, la Comisión Mixta de las Cortes Generales — también en la línea con lo recomendado por el Tribunal de Cuentas y en perfecta sintonía con este órgano- insta a las formaciones políticas a promover el principio de concurrencia de empresas en sus procedimientos de contratación y adjudicación de gastos electorales evitando la concentración en un único proveedor en aras de la optimización de sus recursos ${ }^{19}$. Medida de indudable interés en la eficiencia en el gasto de fondos públicos destinados al sostenimiento de las actividades electorales de los partidos y que se une a la instancia a todas las fuerzas políticas de rendir cuentas al Tribunal acerca de sus contabilidades —ordinarias y electorales - en plazo, y con integridad de su contenido legal obligatorio. Exhortación que podríamos calificar de recapituladora y omnicomprensiva y que hace específica mención a la consignación en estos datos de toda aquella información relativa a subvenciones y donaciones recibidas por cada formación política, así como sobre los créditos recibidos de entidades financieras incluyendo, en su caso, las condonaciones y renegociaciones de los mismos.

19 A propósito del particular ha señalado Gaspar Ariño Ortiz que «cualquier reforma de la financiación de los partidos será insuficiente si no se adoptan medidas para limitar los gastos desenfrenados que éstos generan». Cfr. Gaspar ARIÑo OrTIZ, La financiación de los partidos políticos, op. cit., p. 40. 